\title{
Correction to: Experimental study on strength properties, fracture patterns, and permeability behaviors of sandstone containing two filled fissures under triaxial compression
}

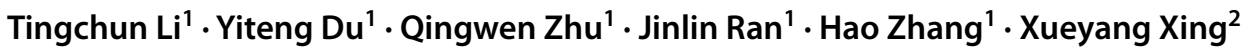 \\ Published online: 25 May 2021 \\ ๑) Springer-Verlag GmbH Germany, part of Springer Nature 2021
}

Correction to: Bulletin of Engineering Geology and the Environment (2021) https://doi.org/10.1007/s10064-021-02286-3

The authors would like to update Fig. 11 and 13. The ordinate titles of some stress-volumetric strain curves in Fig. 11 are misaligned and the positions of (c) (d) and (e) (f) in Fig. 13 need to be swapped.

The original article has been corrected.

The original article can be found online at https://doi.org/10.1007/ s10064-021-02286-3.

Yiteng Du

duyiteng2016@sdust.edu.cn

1 Shandong Key Laboratory of Civil Engineering Disaster Prevention and Mitigation, Shandong University of Science and Technology, Qingdao 266590, China

2 Department of Architectural Engineering, Binzhou University, Binzhou 256600, China 